\title{
Cláusulas sociales y contratación pública: la experiencia del Derecho de la Unión Europea(*)
}

\section{Social clauses and public procurement: the experience of European Union Law}

\author{
Isabel Gallego Córcoles ${ }^{(*)}$ \\ Universidad de Castilla-La Mancha (Castilla-La Mancha, España)
}

\begin{abstract}
Resumen: Aunque en la actualidad la norma de cabecera del Derecho de la Unión Europea proclama que uno de sus objetivos es permitir que los contratantes utilicen mejor la contratación pública en apoyo de objetivos sociales comunes, la realidad demuestra que el reconocimiento de cláusulas sociales en la contratación pública ha experimentado una evolución tortuosa. En las siguientes páginas se analiza dicha evolución, así como se señalan cuáles son las principales dificultades que siguen impidiendo que se haga un uso más social de la contratación pública.
\end{abstract}

Palabras claves: Cláusulas sociales - Contratación pública estratégica - Criterios de adjudicación - Condiciones de ejecución

\begin{abstract}
One of the objectives of the European Union Public Procurement Law is to enable tenderers to make better use of public procurement in support of common social goals. However, the reality shows that the implementation of social clauses in public procurement raises many difficulties. This paper aims to analyze the development of social clauses in public procurement and to identify the obstacles that impede a more social use of public procurement.
\end{abstract}

Key words: Social clauses - Strategic public procurement - Award criteria - Performance conditions

$\left(^{*}\right) \quad$ Nota del editor: El artículo fue recibido el 31 de enero de 2021 y su publicación fue aprobada el 15 de marzo de 2021.

${ }^{* *}$ Licenciada y Doctora en Derecho por la Universidad de Castilla La Mancha (UCLM). Diplomada en la European Academy of Public Law. Profesora Titular de Derecho Administrativo de la UCLM desde 2010, está acreditada a Catedrática desde el año 2020. Ponente en Universidades italianas, británicas y americanas (Universidad de Piura en Perú y Universidad Mayor de San Andrés en Bolivia), ha impartido docencia también en distintos Máster de Universidades españolas. Sus líneas de investigación se han basado principalmente en expropiación forzosa, Derecho de la Contratación Pública y Derecho de Aguas. ORCID: https://orcid.org/00000003-4018-3115. Correo electrónico: isabel.gallego@uclm.es. 


\section{Antecedentes: la progresiva consagración de la contratación pública como instrumento al servicio de políticas ambientales, sociales y de innovación}

En la contratación pública late una indudable tensión entre el servicio al interés público y el principio de libre concurrencia. El Derecho español ha otorgado tradicionalmente una preponderancia casi absoluta al primero de los principios, mientras que el Derecho europeo se inclina decididamente a favor del segundo(1). Todo ello ha supuesto una honda transformación en el instituto de la contratación pública. Así, se le ha despojado de las prerrogativas administrativas, elemento tradicionalmente definitorio del contrato administrativo. Sin embargo, esta evolución no implica que el servicio al interés general quede reducido a su mínima expresión, realizado únicamente a través de la consecución de la libre competencia. Los intereses generales vuelven a teñir la contratación una vez que se reconoce el valor de ésta como instrumento para la consecución de distintos mandatos y principios constitucionales (arts. 1.1 y 45 de la Constitución Española, entre otros) y de diversas políticas públicas.

La contratación pública no puede concebirse exclusivamente como una herramienta de aprovisionamiento de los poderes públicos, sino como un poderoso instrumento para llevar a cabo políticas públicas tan diversas como la promoción de la innovación, el fomento de las Pymes o la sostenibilidad social y ambiental (Gimeno, 2006, p. 16) (2). En este sentido debe advertirse que en el año 2016, la OCDE cuantificó en un $12 \%$ el monto gastado en los países de la OCDE en compras públicas ${ }^{(3)}$. Además, como subraya Gimeno (2014) $)^{(4)}$, ignorar la versatilidad estratégica de la contratación pública supone renunciar al liderazgo institucional que corresponde a los poderes públicos.

Esta visión instrumental de la contratación pública implica la utilización de la contratación pública con el fin de orientar y afianzar comportamientos empresariales beneficiosos para el interés general, sin que necesariamente, estén conectados con la directa satisfacción funcional del contrato (Medina, 2011). De esta forma, se consideran objetivos secundarios o políticas horizontales aquellos objetivos que no justifican la contratación, pero que conllevan aparejada una mejora con respecto a la situación preexistente ${ }^{(5)}$.

Entre estos objetivos se encuentra la compra ecológica, la compra socialmente responsable y de forma algo más reciente, el estímulo a la innovación ${ }^{(6)}$. Por lo que más interesa a este estudio, según el documento de la Comisión Europea, "Guía para tomar en consideración cuestiones sociales en la contratación pública" la compra socialmente responsable se refiere a las operaciones de contratación que "tienen en cuenta uno o más de los siguientes aspectos sociales: oportunidades de empleo, trabajo digno, cumplimiento con los derechos sociales y laborales, inclusión social (incluidas las personas con discapacidad), igualdad de oportunidades, diseño de accesibilidad para todos, consideración de los criterios de sostenibilidad, incluidas las cuestiones de comercio ético y un cumplimiento más amplio de la responsabilidad social de las empresas".

Es este concepto amplio en el que se incluyen "compra pública social" y "compra ética". La llamada "compra pública social" tiene por objeto integrar las inquietudes sociales en los procedimientos de adjudicación de un contrato público al tomar en consideración aspectos como la lucha contra el desempleo, la calidad en el empleo, la perspectiva de género, la contratación de personas con discapacidad o la reserva de contratos a

(1) Entre otros, Meilan (2013, p. 38) y, Moreno y Pleite (2009, p. 63).

(2) En relación con el empleo estratégico de la contratación pública es imprescindible la cita a Gimeno (2014); Pernas (2013); Medina (2011); González (2015).

(3) Datos disponibles en Public Procurement (oecd.org) (fecha de consulta: 1-12-2020). Este porcentaje es sensiblemente mayor en los países Europeos. Véase Comunicación de la Comisión Europea "Conseguir que la contratación pública funcione en Europa y para Europa", 3.10.2017, COM (2017) 572 Final, p. 3.

(4) Como destaca Rodriguez (2013, p. 43), las nuevas políticas públicas sugieren una llamada a la superación del falso dilema públicoprivado, y desde esta óptica, el contratista es también colaborador del sector público para la obtención de resultados sociales, de humanización de la realidad, de fortalecimiento de la dignidad del ser humano y de su entorno.

(5) Sobre todo ello, véase Medina (2011) y la bibliografía allí citada.

(6) La integración formal de la contratación pública en la política más amplia de innovación no se produce hasta 2003 [Véase apartado 5.4 Comunicación de la Comisión "Invertir en investigación: un plan de acción para Europa", COM (2003), 226 FINAL/2, de 4 de junio de 2003]. Sobre los primeros estadios de integración de la política de innovación y la contratación pública, véase entre otros, Edler y Georghiou (2007). 
Empresas de inserción y Centros Especiales de Empleo. Por su parte, la "compra ética" engloba otros supuestos en los cuales los elementos a valorar tienen más que ver con el cumplimiento de estándares éticos establecidos en las convenciones internacionales sobre condiciones laborales dignas, salarios mínimos y derechos de los trabajadores (Medina, 2012)(7).

Desde una perspectiva Europea, el debate sobre la visión instrumental de la contratación pública no es en absoluto novedoso. Ya en el célebre Libro Verde La Contratación pública en la Unión Europea: reflexiones para el futuro ${ }^{(8)}$ se afirmó que "la normativa de contratación pública puede contribuir a lograr los objetivos de las políticas social y medioambiental". No obstante, las dudas sobre la forma de conciliar dichos objetivos con el principio de libre concurrencia fueron recurrentes De este modo, la Directiva 2004/18/CE, de 31 de marzo de 2004, sobre coordinación de los procedimientos de adjudicación de los contratos públicos de obras, de suministro y de servicios, permitió desbrozar el camino al autorizar a los poderes adjudicadores a tener en cuenta aspectos ambientales y sociales en sus procedimientos de adjudicación de contratos, si bien se exigía en su puesta en práctica compatibilizar dichos objetivos con los principios que presiden la contratación pública, esto es, los principios de concurrencia, transparencia, igualdad de trato y no discriminación. En todo caso, como subraya la autora, la voluntad clara y decida por atender objetivos de interés general desde la regulación sobre contratos públicos llega en el año 2001 de la mano de dos Comunicaciones en las que la Comisión analiza las diversas opciones que ofrecía el marco jurídico comunitario entonces vigente para incorporar aspectos sociales y medioambientales en los contratos públicos. Se trata de la Comunicación sobre la legislación comunitaria de contratos públicos y las posibilidades de integrar aspectos medioambientales en la contratación pública [COM (2001) 274 final, de 4 de julio de 2001] y la Comunicación sobre la legislación comunitaria de contratos públicos y las posibilidades de integrar aspectos sociales en dichos contratos [COM (2001) 566 final de 15 de octubre de 2001] (Medina, 2010)(9).

Ahora bien, de forma más reciente el Derecho europeo no sólo se permite, sino que fomenta la utilización estratégica de la contratación pública y, en este rápido recorrido introductorio, la cita a la Estrategia Europa 2020 es inevitable ${ }^{(10)}$. La Estrategia
Europa 2020 afirma con rotundidad que "el año 2010 debe marcar un nuevo principio". Y en el marco de este nuevo comienzo la Comisión propone para la UE cinco objetivos cuantificables para 2020: el empleo, la investigación y la innovación, el cambio climático y la energía, la educación y la lucha contra la pobreza. Al servicio de la consecución de los mismos aparece reiteradamente la contratación pública.

En este contexto, no causa perplejidad que uno de los dos objetivos de la propuesta de Directiva del Parlamento europeo y del Consejo relativa a la contratación pública del año $2011^{(11)}$, consistiese en permitir que los compradores utilicen mejor la contratación pública en apoyo de objetivos sociales comunes como la protección del medio ambiente, una mayor eficiencia energética y en el uso de los recursos, la lucha contra el cambio climático, la promoción de la innovación, el empleo y la integración social y la prestación de servicios sociales de alta calidad en las mejores condiciones posibles.

Estos objetivos se han plasmado en el considerando segundo de la finalmente aprobada Directiva 2014/24/UE, de 26 de febrero, sobre contratación pública y por la que se deroga la Directiva 2004/18/CE. Como se reconoce en dicho considerando:

La contratación pública desempeña un papel clave en la Estrategia Europa 2020, establecida en la Comunicación de la Comisión de 3 de marzo de 2010 titulada "Europa 2020, una estrategia para un crecimiento inteligente, sostenible e integrador" ("Estrategia Europa 2020"), como uno de los instrumentos basados en el mercado que deben utilizarse para conseguir un crecimiento inteligente, sostenible e integrador, garantizando al mismo tiempo un uso más eficiente de los fondos públicos. Con ese fin, deben revisarse y modernizarse

(7) Por su parte, la contratación ecológica se define en la Comunicación de la Comisión Europea Contratación pública para un medio ambiente mejor como "un proceso por el cual las autoridades públicas tratan de adquirir mercancías, servicios y obras con un impacto medioambiental reducido durante su ciclo de vida, en comparación con el de otras mercancías, servicios y obras con la misma función primaria que se adquiririan en su lugar" (COM, 2008, p. 4). En relación con ésta, véase Razquin (2017) y Pernas (2011).

(8) Véase la página 33 de la Comunicación adoptada por la Comisión el 27 de Noviembre de 1996, a propuesta del Señor Monti.

(9) Nos remitimos a este trabajo para un análisis detallado de la progresiva incorporación de los objetivos secundarios a la contratación pública.

(10) Comunicación de la Comisión Europea "EUROPA 2020 Una estrategia para un crecimiento inteligente, sostenible e integrador", Bruselas, 3.3.2010. COM (2010) 2020 final.

(11) COM (2011) 896 final, 2011/0438 (COD). 
las normas vigentes sobre contratación pública adoptadas de conformidad con la Directiva 2004/17/CE del Parlamento Europeo y del Consejo, y la Directiva 2004/18/CE del Parlamento Europeo y del Consejo a fin de incrementar la eficiencia del gasto público, facilitando en particular la participación de las pequeñas y medianas empresas (PYME) en la contratación pública, y de permitir que los contratantes utilicen mejor la contratación pública en apoyo de objetivos sociales comunes.

Y en este ámbito, la nueva Directiva incorpora múltiples herramientas al servicio de la promoción de la contratación ecológica, social y de innovación. Así, sin ánimo de exhaustividad, puede destacarse la regulación de las etiquetas ambientales y sociales, la flexibilización de la vinculación con el objeto del contrato de los criterios de adjudicación, la inclusión del ciclo de vida como criterio de adjudicación, el énfasis en la definición funcional del objeto del contrato, la introducción de una mayor flexibilidad en el empleo del procedimiento de licitación con negociación -que sustituye al negociado con publicidad y al diálogo competitivo- y el diseño de un nuevo procedimiento, la asociación para la innovación, creado específicamente como herramienta para estimular ésta desde la demanda, etc.

La relevancia de esta nueva batería de herramientas dirigidas a la plasmación de una visión estratégica de la contratación pública no debe soslayarse, más aún cuando se constata que existe una voluntad real por parte de las instituciones europeas de que todos estos mecanismos tengan plena efectividad práctica. La Comunicación de la Comisión Europea "Conseguir que la contratación pública funcione en Europa y para Europa"(12) ha llamado la atención sobre el hecho de que los Estados miembros no están utilizando plenamente las posibilidades de la contratación pública como herramienta estratégica para fomentar objetivos de política social sostenibles y la innovación. En consecuencia, la Comisión anuncia nuevas iniciativas tendentes a garantizar una mayor aceptación de la contratación pública estratégica. Entre ellas, actualizar las orientaciones sobre la contratación ecológica y social y ofrecer orientaciones sobre la contratación de innovación.

Ahora bien, en la experiencia europea, la incorporación de cláusulas sociales en la contratación pública ha suscitado un gran número de dudas, que el nuevo marco regulatorio vigente no ha terminado de disipar. Valga como expresivo ejemplo de lo anterior que mientras el Manual Adquisiciones Ecológicas, de la Comisión Europea ha alcanzado ya su tercera edición en abril de 2016, todavía no se ha actualizado la Guía para tomar en consideración cuestiones sociales en la contratación pública ${ }^{(13)}$, publicada en 2010, y que ha quedado totalmente obsoleta tras la aprobación de la Directiva 2014/24/UE. Por el momento, el único documento orientativo es la publicación Making socially responsible public procurement work: 71 good practice cases ("Haciendo que la contratación pública sostenible funcione: 71 buenas prácticas") de la Agencia Ejecutiva para las Pequeñas y Medianas Empresas de la Comisión Europea (EASME, por sus siglas en inglés) ${ }^{(14)}$.

El objetivo de estas páginas es analizar de forma crítica el tortuoso camino que está recorriendo el Derecho europeo hacia la admisión de la contratación pública como un instrumento de política social. Como en otros ámbitos de la contratación pública, la ausencia de una regulación expresa primero y de una normativa detallada después en las sucesivas Directivas sobre contratación pública ha propiciado que haya sido la jurisprudencia del Tribunal de Justicia de la Unión Europea la que ha marcado las principales pautas en el reconocimiento de la posibilidad de utilizar cláusulas sociales en la contratación pública. Por ello en este trabajo se prestará especial atención a la misma, eludiendo realizar una exhaustiva exégesis del marco legal, con el objetivo de prestar atención exclusivamente a aquellos elementos que han resultado realmente conflictivos.

\section{La admisión de las cláusulas sociales en la contratación pública en la vacilante doctrina del tribunal de justicia de la unión europea}

\subsection{El punto de partida: distintas fases, distintas posibilidades de incorporación de cláusulas sociales}

(12) Véase la página 4 de la Comunicación de 3.10.2017, COM (2017) 572 Final.

(13) SEC (2010) 1258 final, de 19 de octubre de 2010.

(14) Este documento es del año 2020. La recopilación de casos prácticos pretende mejorar el conocimiento y comprensión del potencial de la contratación pública socialmente responsable, mostrando 71 ejemplos de cómo los compradores públicos han obtenido beneficios sociales en la práctica. Este estudio pretende difundir modelos de procedimientos de licitación y políticas públicas adecuados con el fin de estimular su réplica en distintas partes de Europa. El estudio refleja la opinión de los autores, sin que necesariamente coincida con la de la EASME. En todo caso, se anuncia que la Comisión está trabajando en la actualización de la Guía Adquisiciones sociales, cuya nueva versión se preveía que estuviera publicada ese mismo año. 
La primera sentencia europea que aborda la posibilidad de incorporar cláusulas sociales a la contratación pública fue la STJUE de 20 de septiembre de 1988, Asunto C-31/87, Gebroeders Beentjes. Este pronunciamiento tiene su origen en una cuestión prejudicial suscitada en el litigio emprendido por una empresa que fue excluida de un procedimiento de licitación porque, entre otras razones, a juicio del órgano de contratación "no parecía en condiciones de emplear a trabajadores en paro prolongado".

Pues bien, en el marco de este litigio el TJUE niega tajantemente que la cláusula "condiciones de emplear a trabajadores en paro prolongado" pueda válidamente incluirse como criterio de solvencia o como criterio de adjudicación. Así (apartado 28):

Por lo que respecta a la exclusión de un licitador por no estar, a juicio del órgano de contratación, en condiciones de emplear a trabajadores en paro prolongado, debe señalarse que tal requisito no guarda relación ni con la verificación de la aptitud de los contratistas por su capacidad económica, financiera y técnica, ni con los criterios de adjudicación del contrato a que alude el artículo 29 de la Directiva.

La cláusula, según la sentencia que reseñamos, podría en todo caso incluirse como condición de ejecución del contrato. Pero ello siempre que cumpla un doble requisito: a) que respete el principio de publicidad, es decir, que esté incluido en el anuncio de licitación y b) que no resulte discriminatoria. Así,

La condición de emplear trabajadores en paro prolongado es compatible con la Directiva si no incide de forma discriminatoria directa o indirectamente por lo que respecta a los licitadores de otros Estados miembros de la Comunidad. Esta condición específica adicional debe obligatoriamente ser mencionada en el anuncio del contrato.

$Y$ lo cierto es que el propio Tribunal considera que una cláusula de este tipo puede eventualmente encerrar una discriminación indirecta hacia las empresas no nacionales. En los términos de la citada sentencia:

La exigencia de emplear trabajadores en paro prolongado podría, en concreto, infringir el principio de no discriminación por razón de la nacionalidad consagrado en el apartado 2 del artículo 7 del Tratado, en el caso de que se comprobara que sólo los licitadores nacionales pueden cumplir tal condición o bien que su cumplimiento resulta mucho más difícil en el caso de los licitadores de otros Estados miembros. Corresponde al Juez nacional comprobar, habida cuenta de todas las circunstancias del caso, si la exigencia de dicho requisito tiene o no una incidencia discriminatoria directa o indirecta.

En definitiva, el Tribunal de Justicia excluye como criterio de adjudicación contractual un criterio relativo a la "lucha contra el desempleo", pero considera aceptable y compatible con el Derecho comunitario una condición vinculada al empleo de trabajadores en paro prolongado, calificándola de condición específica adicional, siempre que no resulte discriminatoria y que tal condición se mencione en el anuncio de licitación (apartado 36).

No obstante, las sentencias posteriores no han sido totalmente coherentes con este punto de partida, tanto por defecto como por exceso. Esto debido a que, por un lado, han admitido una cláusula social relativa al desempleo como criterio de adjudicación. Por otro lado, se ha rechazado una cláusula relativa al cumplimiento de convenios colectivos como condición de ejecución, por lo que la aparente mayor flexibilidad para incluir cláusulas sociales como condición de ejecución quedó pronto cuestionada en la práctica.

\subsection{Las cláusulas sociales como criterios de adjudicación en la jurisprudencia del TJUE}

2.2.1. Primeras dudas: La paradójica admisión de un criterio de adjudicación relativa a la lucha contra el desempleo

Apenas dos años después de la sentencia Gebroeders Beentjes, el Tribunal Europeo tuvo oportunidad de pronunciarse de nuevo sobre uno de los caballos de batalla del Derecho español: la posibilidad de incorporar cláusulas sociales como criterios de adjudicación ${ }^{(15)}$. En relación con esta cuestión, la STJUE de 26 de septiembre de 2000, C-225/98, analizó el recurso interpuesto por la Comisión europea contra Francia, entre otros aspectos y por lo que aquí interesa, por incluir explícitamente como criterio de adjudicación una condición relativa al empleo relacionada con una acción local de lucha contra el desempleo. La Comisión defendía, precisamente, que dicho criterio vulneraba el artículo 30, apartado 1, de la Directiva 93/37. El precepto, con un tenor asimilable al artículo 53 Directiva 2004/18/CE, establecía que los criterios en que ha de basarse el órgano de contratación para la adjudicación de los contratos son bien únicamente el precio más bajo, bien, en el caso de que la adjudicación se efectúe a la oferta económicamente más ventajosa, distintos criterios que varían en función del

(15) Hemos tenido ocasión de analizar esta problemática con profundidad en Gallego (2019). 
contrato, como el precio, el plazo de ejecución, el coste de utilización, la rentabilidad y el valor técnico.

Dado el precedente jurisprudencial ya existente, y el tenor literal del precepto, podría haberse vaticinado el éxito del recurso interpuesto por la Comisión. No obstante, el TJUE considera la cláusula adecuada al Derecho de la Unión Europea. Así:

No obstante, esta disposición no excluye la posibilidad de que los órganos de contratación utilicen como criterio una condición relacionada con la lucha contra el desempleo, siempre que ésta respete todos los principios fundamentales del Derecho comunitario y, en particular, el principio de no discriminación que se deriva de las disposiciones del Tratado en materia de derecho de establecimiento y de libre prestación de servicios (...).

En lo que atañe a la alegación formulada por la Comisión según la cual la sentencia Beentjes, antes citada, se refería a una condición de ejecución del contrato y no a un criterio de adjudicación de éste, basta con señalar que, tal como se deriva claramente del apartado 14 de la sentencia Beentjes, antes citada, la condición de contratar a parados de larga duración, sobre la que versaba dicho asunto, había servido de base para la exclusión de un licitador, por lo que sólo podía constituir un criterio de adjudicación del contrato.

En el caso de autos, tal como se indica en el apartado 48 de la presente sentencia, la Comisión sólo pone en entredicho la mención de tal criterio como criterio de adjudicación en el anuncio de licitación. No alega que el criterio de lucha contra el desempleo no respete los principios fundamentales del Derecho comunitario, en particular el principio de no discriminación, ni que no se haya publicado en el anuncio de licitación.

Puede advertirse, por tanto, que en la sentencia se introduce un giro en la jurisprudencia anterior ${ }^{(16)}$ que no está suficientemente motivado, pues el segundo de los párrafos reseñados es de difícil inteligencia. En aquel momento, la Comisión Europea era muy reacia a admitir cláusulas sociales como criterios de adjudicación. En su interpretación de esta sentencia, subrayó así que esta condición se consideraba como un criterio accesorio no determinante después de comparar las ofertas desde un punto de vista puramente económico ${ }^{(17)}$. Por ello, en la Guía de 2010 sobre incorporación de cuestiones sociales en la contratación pública ${ }^{(18)}$, la Comisión realizó un importante esfuerzo para deslindar los criterios de adjudicación de carácter social que guardan una relación directa con el objeto del contrato de aquellos que no lo tienen. Solo serían admisibles los primeros.

Se señala así que los criterios individuales que determinarán la oferta económicamente más ventajosa o de mejor valor deberán formularse de manera tal que: (i) Estén vinculados al objeto del contrato que se va a adquirir (según se describe en las especificaciones técnicas)(19); (ii) Permitan evaluar las licitaciones según sus criterios cualitativos y económicos en todos sus sectores a fin de determinar cuál es la oferta económicamente más ventajosa. Y se facilitan ejemplos de cláusulas admisibles y cláusulas que no lo son. Respetaría así el Derecho de la Unión que en una contratación pública para la atención de personas con discapacidad, los criterios de adjudicación puedan tener encuentra requisitos relativos a satisfacer las necesidades específicas de cada categoría de usuario (por ejemplo, personalización del servicio según la edad, el sexo o las dificultades sociales de los usuarios, etc.).

Sin embargo, no sería posible utilizar criterios de adjudicación relacionados con la creación de nuevos puestos de trabajo en el mercado local, pues un criterio de ese tipo no está vinculado al objeto del contrato (por ejemplo, la construcción de una obra). Esta forma de comprender la vinculación de la cláusula social con el objeto del contrato queda completamente desautorizada por la sentencia que reseñamos a continuación.

\subsubsection{Una aclaración imprescindible: ¿En qué consiste la vinculación de la cláusula social con el objeto del contrato?}

La relevante STJUE de 10 de mayo de 2012, Comisión c. Países Bajos, as. C-368/10(20) analiza la compatibilidad con el Derecho de

(16) Como afirmara Medina (2012) esta sentencia implica avanzar un paso respecto a la sentencia Gebroeders Beentjes.

(17) Comunicación interpretativa sobre la legislación comunitaria de contratos públicos y las posibilidades de integrar aspectos sociales en dichos contratos, COM (2001) 566 final.

(18) Véase la página 37 de la Guía para tomar en consideración cuestiones sociales en la contratación pública. SEC (2010) 1258 final, de 19 de octubre de 2010.

(19) Las especificaciones técnicas definen el nivel de cumplimiento exigido (por ejemplo, normas de accesibilidad en las especificaciones técnicas) En este sentido, el documento destaca que la entidad adjudicadora puede decidir que se otorguen puntos adicionales en la etapa de adjudicación a cualquier producto o servicio cuyo rendimiento sea mejor al del nivel mínimo. Por ejemplo, cuando se hace referencia a una norma de accesibilidad, por ejemplo a la web como en el caso de la norma UNE 139803 "Requisitos de accesibilidad para contenidos Web" (España), es posible cumplir en tres niveles: A, AA o AAA. Se podrían otorgar puntos adicionales a la oferta que alcanza el nivel más alto.

(20) En relación con esta sentencia, véase Medina (2013). 
la Unión de la exigencia de una etiqueta ecológica (EKO) y una etiqueta relativa al comercio justo (MAX HAVELAAR) en el marco del procedimiento de adjudicación de un contrato de suministro de té y café licitado por una provincia holandesa. La sentencia reviste particular interés porque examina si estas etiquetas eran admisibles tanto como especificación técnica, criterio de adjudicación y como requisito de capacidad técnica.

En lo que a los criterios de adjudicación respecta, aunque a este supuesto es aplicable ratione temporis la posterior Directiva 2004/18/CE, que exige expresamente que el criterio de adjudicación se encuentre vinculado con el objeto del contrato [Artículo $53.1 \mathrm{a}]^{(21)}$, la sentencia introduce una interpretación del Derecho de la contratación pública europeo que supera las concepciones más estrictas de la vinculación de los criterios de adjudicación con el objeto del contrato que reseñamos en el epígrafe anterior.

Esto se debe a que, por un lado, se admite que los poderes adjudicadores puedan elegir criterios de adjudicación basados en consideraciones de carácter social que se refieren a personas distintas de los usuarios de las obras, suministros y servicios objeto del contrato. Y ello pese a que el considerando cuadragésimo sexto de la Directiva 2004/18/CE literalmente se refería a que "el poder adjudicador podrá regirse por criterios destinados a satisfacer exigencias sociales que, en particular, respondan necesidades -definidas en las especificaciones del contrato- propias de las categorías de población especialmente desfavorecidas a las que pertenezcan los beneficiarios/usuarios objeto del contrato". Por otro lado, se entiende que una etiqueta social presenta con el contrato controvertido el vínculo exigido por el artículo 53.1 a) de la Directiva 2004/18/CE. Y es que:

Para apreciar el fundamento de la imputación relativa a la falta de un vínculo suficiente entre el criterio de adjudicación controvertido y el objeto del contrato, es preciso, por una parte, tener en cuenta los criterios en que se basan las etiquetas EKO y MAX HAVELAAR. (...) dichos criterios caracterizan productos procedentes de la agricultura ecológica y del comercio justo, respectivamente. (...). En cuanto al comercio justo, (...) resulta que los criterios impuestos por la fundación que concede la etiqueta MAX HAVELAAR tienen por objeto favorecer a los pequeños productores de los países en desarrollo al mantener con ellos relaciones comerciales que tienen en cuenta las necesidades reales de dichos productores, y no sólo las leyes del mercado. De estas indicaciones se desprende que el criterio de adjudicación controvertido se refería a características medioambientales y sociales comprendidas en el ámbito de aplicación del artículo 53, apartado 1, letra a), de la Directiva 2004/18

Por otra parte, procede señalar que, con arreglo a la descripción del contrato que figura en el subcapítulo 1.4 del pliego de condiciones, ese contrato tenía por objeto, en particular, el suministro del café, el té y otros ingredientes necesarios para la elaboración de las bebidas disponibles en las máquinas expendedoras. Además, de la redacción del criterio de adjudicación controvertido resulta que éste sólo se refería a los ingredientes que se suministraran en el marco de dicho contrato, sin ninguna implicación con respecto a la política general de compras de los licitadores. Por consiguiente, esos criterios se referían a productos cuyo suministro constituía una parte del objeto de dicho contrato.

Por último, como se desprende del punto 110 de las conclusiones de la Abogado General, no es necesario que un criterio de adjudicación se refiera a una característica intrínseca de un producto, es decir, a un elemento incorporado materialmente en éste $(\ldots)^{(22)}$.

De esta forma, aunque materialmente no se haya incorporado al producto, las condiciones de comercialización del producto tienen para el Tribunal una clara y especifica relación con el objeto del contrato. En este punto, es difícil expresar la vinculación entre el objeto del contrato y su proceso de elaboración y comercialización de una forma más sugerente a la reflejada en las conclusiones de la Abogado General Kokott(23). Como se afirma de forma magistral, "aunque el sabor del azúcar, en sentido estricto, no es diferente en función de si ha sido adquirido de forma justa o injusta, un producto que ha llegado al mercado en condiciones injustas deja un regusto más amargo en el paladar de los clientes conscientes de la responsabilidad social".

(21) Dispone este precepto que "sin perjuicio de las disposiciones legales, reglamentarias o administrativas nacionales relativas a la remuneración de determinados servicios, los criterios en que se basarán los poderes adjudicadores para adjudicar los contratos públicos serán:

a) bien, cuando el contrato se adjudique a la oferta económicamente más ventajosa desde el punto de vista del poder adjudicador, distintos criterios vinculados al objeto del contrato público de que se trate: por ejemplo, la calidad, el precio, el valor técnico, las características estéticas y funcionales, las características medioambientales, el coste de funcionamiento, la rentabilidad, el servicio posventa y la asistencia técnica, la fecha de entrega y el plazo de entrega o de ejecución".

(22) En todo caso, la cláusula controvertida se declara contraria al Derecho de la Unión puesto que no se garantizaron los principios de igualdad y transparencia, ya que ni se indicaron los criterios en los que se basa la etiqueta cuestionada ni se autorizó que se presentara a través de cualquier medio adecuado la prueba de que un producto reúne esos criterios.

(23) Conclusiones presentadas el 15 de diciembre de 2011. 


\subsection{Las cláusulas sociales como condición de ejecución: La encrucijada del Derecho social europeo}

Una herramienta con gran potencialidad para lograr objetivos secundarios en la contratación pública es el establecimiento de obligaciones concretas de cara a la ejecución del contrato. De hecho, el artículo 26 de la Directiva 2004/18/CE ya establecía que los poderes adjudicadores podían exigir condiciones especiales en relación con la ejecución del contrato siempre que estas sean compatibles con el Derecho comunitario y se indiquen en el anuncio de licitación o en el pliego de condiciones, en clara recopilación de la doctrina de la sentencia Beentjes. Además, añadía el precepto, "las condiciones en que se ejecute un contrato podrán referirse, en especial, a las consideraciones de tipo social y medioambiental". En este sentido, la Comisión europea afirmaba que condiciones de ejecución del contrato constituyen, generalmente, la etapa más apropiada del procedimiento para incluir aspectos sociales relacionados con cuestiones de empleo y condiciones laborales de los trabajadores involucrados en la ejecución del contrato ${ }^{(24)}$.

Por todo ello, no dejó de sorprender que la STJUE de 3 de abril de 2008, asunto C-346/06, Rüffert, considerase incompatible con el Derecho de la Unión una condición de ejecución relativa al salario de los trabajadores que debía emplear la empresa adjudicataria. En efecto, la sentencia analizó si era compatible con el Derecho europeo la norma de un Land alemán según la cual los contratos de obras solo podrán adjudicarse a las empresas que en la licitación se comprometiesen por escrito a pagar a sus trabajadores, como mínimo, la retribución establecida en el convenio colectivo aplicable en el lugar de la prestación de tales servicios.

Pues bien, el Tribunal europeo consideró esa cláusula inadmisible, ya que el artículo 8 Directiva 96/71/CE sobre el desplazamiento de trabajadores efectuado en el marco de una prestación de servicios solo permite establecer salarios mínimos por referencia a convenios colectivos cuando estos tengan alcance general. Dado que el convenio aplicable en el asunto controvertido se refería exclusivamente a "Edificios y Obras Públicas", el TJUE concluye que no se trata de un convenio de tal naturaleza. De esta forma, el Tribunal no opera, ni mucho menos, con excesiva generosidad al fijar el término de referencia -sector de la construcción, en lugar de sector de la obra pública-. En definitiva, en la argumentación de la sentencia Rüffert no se realiza remisión alguna a la normativa sobre contratación pública, que probablemente hubiera permitido abordar esta problemática adoptando una solución distinta ${ }^{(25)}$. Baste recordar que el considerando 34 de la Directiva 2004/18/ CE consideraba expresamente la normativa social aplicada como una regulación de mínimos $^{(26)}$.

Al margen de ello, se han planteado dudas en relación con la posibilidad de que la normativa de un Estado miembro establezca salarios mínimos en caso de deslocalización de los servicios ${ }^{(27)}$. En este sentido, la STJUE de 18 de septiembre de 2014, as C-549/13, Bundesdruckerei, analizó si era compatible con el Derecho de la Unión determinada norma alemana que imponía a los licitadores y a sus subcontratistas que se comprometiesen a pagar al personal que ejecute las prestaciones objeto del contrato público un salario mínimo. La controversia surge ante la decisión de determinado órgano de contratación de exigir esta condición a un operador económico que tenía intención de subcontratar la ejecución del contrato a una empresa radicada en Polonia, lugar donde exclusivamente iba a realizarse la prestación.

EI TJUE concluyó que en una situación en la que un licitador tiene previsto ejecutar

(24) Guía para tomar en consideración cuestiones sociales en la contratación pública. SEC (2010) 1258 final, de 19 de octubre de 2010.

(25) Comparto en este punto las consideraciones en este punto realizadas por Medina (2013, p. 229 y ss).

(26) En concreto, el considerando 34 de la Directiva afirma literalmente que: "las leyes reglamentaciones y convenios colectivos, tanto nacionales como comunitarios, vigentes en materia de condiciones de trabajo y de seguridad del trabajo, se aplicarán durante la ejecución de un contrato público, siempre que dichas normas, así como su aplicación, se ajusten al Derecho comunitario. Para las situaciones transfronterizas, en las que los trabajadores de un Estado miembro prestan sus servicios en otro Estado miembro para la realización de un contrato público, la Directiva 96/71/CE del Parlamento Europeo y del Consejo, de 16 de diciembre de 1996 sobre el desplazamiento de trabajadores efectuado en el marco de una prestación de servicios, enuncia las condiciones mínimas que han de respetarse en el país de acogida en relación con dichos trabajadores desplazados".

(27) La Resolución 83/2015 de 12 de junio de 2015 del Tribunal de Contratación Pública de la Comunidad de Madrid explica que la deslocalización consiste en el traslado de una actividad productiva a otros países de menor nivel de desarrollo, para beneficiarse de los menores costes fiscales y de la mano de obra en ellos y supone la sustitución de empleo nacional por extranjero que amenaza el tejido productivo y el trabajo en los países más avanzados donde se producen pérdidas de capital y empleo que entra en competición con el de las economías menos desarrolladas. El efecto más importante es la pérdida de puestos de trabajo en origen, en el país al que van dirigidos los suministros o servicios, donde aumenta el gasto social para atender ese desempleo y la recalificación profesional de los trabajadores. 
un contrato público exclusivamente con trabajadores empleados por un subcontratista establecido en un Estado miembro distinto del de la entidad adjudicadora, el derecho a la libre prestación de servicios (artículo 56 TFUE) se opone a la aplicación de una normativa del Estado miembro de esa entidad adjudicadora que obliga a ese subcontratista a pagar a los citados trabajadores un salario mínimo fijado por dicha normativa. En definitiva, las normas sobre el mercado interior europeo impiden que se puedan disponer medidas tendentes a dificultar la deslocalización de servicios en el ámbito de la Unión Europea. No obstante, como se ha señalado en alguna Resolución española, este tipo de medidas sí podrían ser admisibles cuando la prestación del servicio se traslada fuera del ámbito territorial de la Unión ${ }^{(28)}$.

\section{Directiva 2014/24/EU: principales novedades en la regulación de las cláusulas sociales}

La norma de cabecera del Derecho de la contratación pública europeo, la Directiva 2014/24/EU, tiene como uno de sus objetivos permitir que los contratantes utilicen mejor la contratación pública en apoyo de objetivos sociales comunes. Ello implica que se introduzcan cambios sustanciales en relación con la posibilidad de utilización de la contratación pública de forma estratégica, muchos de los cuales tienen su origen en la jurisprudencia europea que acabamos de analizar.
En primer lugar, la vocación más social de la Directiva 2014/24/UE se refleja ya en los principios de la contratación. La Directiva 2014/18/CE se limitaba a enunciar que los poderes adjudicadores darán a los operadores económicos un tratamiento igualitario y no discriminatorio y obrarán con transparencia(29). Frente a ello, el artículo 18 de la Directiva 2014/24/UE tiene un contenido más ambicioso y así se establece que los Estados miembros tomarán las medidas pertinentes para garantizar que, en la ejecución de contratos públicos, los operadores económicos cumplen las obligaciones aplicables en materia medioambiental, social o laboral establecidas en el Derecho de la Unión, el Derecho nacional, los convenios colectivos o por las disposiciones de Derecho internacional medioambiental, social y laboral enumeradas en el anexo $X^{(30)}$. Además, el citado artículo 18 introduce un nuevo principio, de especial relevancia en el ámbito de la configuración de las cláusulas sociales: el principio de proporcionalidad.

Por otro lado, entre las novedades de Directiva 2014/24/UE ha de destacarse que

(28) Así, la citada Resolución 83/2015 del Tribunal de Contratación Pública de la Comunidad de Madrid afirma que “(...) en los supuestos de deslocalización nos referimos a un supuesto distinto cual es la prestación de servicios en un país no comunitario con destino a España. Como hemos dicho la normativa de contratación admite que empresarios extranjeros participen en licitaciones nacionales compitiendo para prestar un servicio desde su país de origen con destino España. Pero cuando es un nacional el que licita compitiendo con otros nacionales, el recurso a la deslocalización para prestar servicios no en el país de asiento sino en el de destino de los servicios que es el nacional, podría suponer un fraude de ley que distorsiona el principio de libre competencia en cuyo caso la oferta debería ser rechazada".

(29) La necesidad de que en la ejecución de los contratos públicos se respetara el Derecho social y laboral se contenía exclusivamente en el considerando 34 de la Directiva, según el cual "las leyes, reglamentaciones y convenios colectivos, tanto nacionales como comunitarios, vigentes en materia de condiciones de trabajo y de seguridad del trabajo, se aplicarán durante la ejecución de un contrato público, siempre que dichas normas, así como su aplicación, se ajusten al Derecho comunitario (...)".

(30) En concreto:

Convenio OIT 87 sobre la libertad sindical y la protección del derecho de sindicación,

Convenio OIT 98 sobre el derecho de sindicación y de negociación colectiva,

Convenio OIT 29 sobre el trabajo forzoso,

Convenio OIT 105 sobre la abolición del trabajo forzoso,

Convenio OIT 138 sobre la edad mínima,

Convenio OIT 111 sobre la discriminación (empleo y ocupación),

Convenio OIT 100 sobre igualdad de remuneración,

Convenio OIT 182 sobre las peores formas de trabajo infantil,

Convenio de Viena para la protección de la capa de ozono y su Protocolo de Montreal relativo a las sustancias que agotan la capa de ozono,

Convenio para el control de la eliminación y el transporte transfronterizo de residuos peligrosos (Convenio de Basilea), Convenio de Estocolmo sobre contaminantes orgánicos persistentes (COP),

Convenio de Rotterdam sobre el procedimiento de consentimiento fundamentado previo aplicable a ciertos plaguicidas y productos químicos peligrosos objeto de comercio internacional (PNUMA/FAO) (Convenio PIC), Rotterdam, 10 de septiembre de 1998, y sus tres Protocolos regionales. 
las características sociales se incluyen expresamente como aspectos que pueden incluir los criterios de adjudicación. Establece así el artículo 67.2 de la Directiva que "la oferta económicamente más ventajosa desde el punto de vista del poder adjudicador se determinará sobre la base del precio o coste, utilizando un planteamiento que atienda a la relación coste-eficacia (...) y podrá incluir la mejor relación calidad-precio, que se evaluará en función de criterios que incluyan aspectos cualitativos, medioambientales y/o sociales vinculados al objeto del contrato público de que se trate".

Sin embargo, quizá el elemento más reseñable en la nueva regulación no es esta mención expresa. No desaparece en la Directiva la exigencia de que el criterio de adjudicación esté vinculado al objeto del contrato. Sin embargo, y esta aclaración es de gran interés práctico, este requisito se flexibiliza, de forma que esta vinculación no implica que el elemento objeto de valoración se incorpore físicamente a la prestación. Se codifica así la doctrina de la sentencia Comisión contra Países Bajos antes citada. Como se afirma en el considerando 97 de la Directiva, la condición de que exista un vínculo con el objeto del contrato excluye los criterios y condiciones relativos a la política general de responsabilidad corporativa, lo cual no puede considerarse como un factor que caracterice el proceso específico de producción o prestación de las obras, suministros o servicios adquiridos. En consecuencia, los poderes adjudicadores no pueden estar autorizados a exigir a los licitadores que tengan establecida una determinada política de responsabilidad social o medioambiental de la empresa.

\section{De esta forma, el artículo 67.3 de la Directiva establece que:}

Se considerará que los criterios de adjudicación están vinculados al objeto del contrato público cuando se refieran a las obras, suministros o servicios que deban facilitarse en virtud de dicho contrato, en cualquiera de sus aspectos y en cualquier etapa de su ciclo de vida, incluidos los factores que intervienen: a) en el proceso específico de producción, prestación o comercialización de las obras, suministros o servicios; b) en un proceso específico de otra etapa de su ciclo de ida, incluso cuando dichos factores no formen parte de su sustancia material".

Las dificultades han surgido a la hora de determinar en qué consiste un "proceso específico de producción y prestación". Y las dudas se han planteado porque no existe referencia a las condiciones laborales de los trabajadores empleados en la ejecución del contrato como criterio de adjudicación en el artículo 67.3 de la Directiva. Dicho en otros términos, de los considerandos de la Directiva se desprende que puede favorecerse la contratación de sectores desfavorecidos de la población a través de la inclusión de criterios de adjudicación que permitan valorar la contratación laboral con colectivos con dificultades para acceder al mercado de trabajo. Ahora bien, no se aclara expresamente si a través de la contratación pública, pueden mejorarse las condiciones laborales de los trabajadores que van a realizar la prestación.

Por otro lado, la posibilidad de incluir cláusulas sociales como condición de ejecución se contemplaba ya en la derogada Directiva 2004/18/CE. A diferencia de aquella

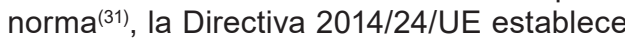
expresamente que las condiciones de ejecución deben estar igualmente vinculadas con el objeto del contrato. Así, según su artículo 70 , "los poderes adjudicadores podrán establecer condiciones especiales relativas a la ejecución del contrato, siempre que estén vinculadas al objeto del contrato, en el sentido del artículo 67, apartado 3 , y se indiquen en la convocatoria de licitación o en los pliegos de la contratación. Dichas condiciones podrán incluir (...), consideraciones de tipo medioambiental, social, o relativas al empleo". De esta forma, la condición de ejecución debe respetar el mismo canon de vinculación con el objeto del contrato, como resalta el considerando 99 de la Directiva(32), que los criterios de adjudicación. Ello supone la superación definitiva de la doctrina Beentjes y de todas las interpretaciones que le han seguido que habían sugerido que existe un

(31) Según su artículo 26, "los poderes adjudicadores podrán exigir condiciones especiales en relación con la ejecución del contrato siempre que éstas sean compatibles con el Derecho comunitario y se indiquen en el anuncio de licitación o en el pliego de condiciones. Las condiciones en que se ejecute un contrato podrán referirse, en especial, a consideraciones de tipo social y medioambiental".

(32) Así, "las medidas destinadas a proteger la salud del personal que participa en el proceso de producción, a favorecer la integración social de las personas desfavorecidas o de los miembros de grupos vulnerables entre las personas encargadas de ejecutar el contrato o a ofrecer formación para adquirir las competencias necesarias para el contrato de que se trate podrán también estar sujetas a criterios de adjudicación o a condiciones de adjudicación (sic.) de un contrato siempre que se refieran a las obras, suministros o servicios que hayan de facilitarse con arreglo al contrato en cuestión. Por ejemplo, dichos criterios o condiciones podrán referirse, entre otras cosas, al empleo para los desempleados de larga duración o a la aplicación de medidas en materia de formación para los desempleados o los jóvenes durante la ejecución del contrato que vaya a adjudicarse. En las especificaciones técnicas los poderes adjudicadores pueden establecer aquellos requisitos sociales que caractericen el producto o el servicio de que se trate, como la accesibilidad para las personas con discapacidad o el diseño para todos los usuarios". 
mayor potencial para la utilización de cláusulas sociales como condiciones de ejecución que como criterios de adjudicación.

Desde la perspectiva de la posibilidad de establecer mejoras en las condiciones laborales de los trabajadores adscritos a la ejecución del contrato público como condición de ejecución, la Directiva 2014/24/UE puede empañar aún más esta posibilidad, ya que desaparece la mención al carácter de normativa de mínimos que la Directiva 96/71/CE tenía en el considerando 34 de la Directiva 2004/18/CE ${ }^{(33)}$. Frente a ello, el considerando 37 de la nueva norma dispone que "las medidas pertinentes se deben aplicar con arreglo a los principios básicos del Derecho de la Unión, en especial para velar por la igualdad de trato. Dichas medidas pertinentes se deben aplicar de conformidad con la Directiva 96/71/CE del Parlamento Europeo y del Consejo y de una forma que garantice la igualdad de trato y no discrimine, directa o indirectamente, a los operadores económicos y a los trabajadores de otros Estados miembros". Sobre esta cuestión, se insiste en el considerando 98 de la Directiva 2014/24/UE(34).

Como ha señalado Arrowsmith $(2014)^{(35)}$, la clara simetría establecida entre criterios de adjudicación y condiciones de ejecución que establece la Directiva 2014/24/UE muestra la admisibilidad de este tipo de consideraciones sociales como criterios de adjudicación, siempre y cuando se refieren a la ejecución de la concreta prestación y no de otro tipo de actividades del operador económico. De esta forma, como señala la autora que seguimos en este punto, este tipo de criterios vinculados a las condiciones laborales estarían bien incluidos en el concepto de "prestación", bien habría que entender que el listado del artículo 67.3 no es exhaustivo, tal y como por otro lado, se desprende tanto del tenor literal de dicho artículo como del considerando $92^{(36)}$.

Finalmente, en lo que respecta a las cautelas que frente a la deslocalización de servicios pueden establecerse en el ámbito de la Unión Europea, en los considerandos de la Directiva se codifica el contenido de la sentencia Bundesdruckerei. Según el considerando 38 de la Directiva, debe considerarse que los servicios se prestan en el lugar en el que se ejecutan las prestaciones características. Cuando los servicios que se presten a distancia, por ejemplo, servicios prestados por centros de atención telefónica, debe considerarse que dichos servicios se prestan en el lugar en el que se realizan los servicios, con independencia de los lugares y Estados miembros a los que se dirijan los servicios.

En definitiva, uno de los aspectos más relevantes de la nueva regulación europea es que se intenta potenciar la utilización de la contratación pública para la consecución de objetivos de carácter social, partiendo de la codificación de la jurisprudencia del Tribunal de Justicia de la Unión Europea, que se incorpora a la norma sin grandes matizaciones. Desde un punto de vista más técnico, una de las principales aportaciones de la Directiva 2014/24/EU es que se dota a los poderes adjudicadores de una mayor flexibilidad a la hora de incorporar las cláusulas sociales, de forma que podrán valorar su incorporación bien como criterio de adjudicación -lo que en el pasado había resultado muy controvertidobien como condición de ejecución. Si se incorpora como criterio de adjudicación es factible que resulte adjudicatario un licitador que no adquiera el compromiso social. El hecho de que la cláusula social no deba cumplirse ya obligatoriamente por todos los licitadores puede vencer las resistencias de determinados poderes adjudicadores a incorporar cláusulas sociales. Por ello, la nueva disciplina europea merece una crítica favorable.

(33) Así, según el considerando 37 de la nueva Directiva, "las medidas pertinentes se deben aplicar de conformidad con la Directiva 96/71/ CE del Parlamento Europeo y del Consejo y de una forma que garantice la igualdad de trato y no discrimine, directa o indirectamente, a los operadores económicos y a los trabajadores de otros Estados miembros".

(34) Según éste: "es fundamental que los criterios de adjudicación o las condiciones de ejecución de un contrato relacionados con los aspectos sociales del proceso de producción se refieran a las obras, suministros o servicios que hayan de facilitarse con arreglo al contrato de que se trate. Además, deberían aplicarse de conformidad con la Directiva 96/71/CE, según es interpretada por el Tribunal de Justicia de la Unión Europea, y no elegirse o aplicarse de una forma que discrimine, directa o indirectamente, a los operadores económicos de otros Estados miembros o de terceros países que sean parte en el ACP o en los Acuerdos de Libre Comercio en los que la Unión sea parte. Por consiguiente, los requisitos que afecten a las condiciones básicas de trabajo reguladas por la Directiva 96/71/CE, como las cuantías de salario mínimo, deben seguir situándose en el nivel establecido por la legislación nacional o por convenios colectivos que se aplican de conformidad con el Derecho de la Unión en el contexto de dicha Directiva".

(35) Enfatiza igualmente el carácter simétrico de la regulación Bordalo (2014, p. 130). El paralelismo entre criterios de adjudicación y condiciones de ejecución, en todo caso, está igualmente claramente establecido en los considerando 93,97 y 99.

(36) En efecto, en dicho considerando se alude expresamente a que "en el contexto de la mejor relación calidad-precio, la presente Directiva incluye una lista no exhaustiva de posibles criterios de adjudicación que incluyen aspectos sociales y medioambientales". Véase Diez (2017, p. 216). 
En todo caso, a la hora de diseñar una concreta licitación deberá valorarse cuidadosamente cuál es la naturaleza más idónea, en el contexto de dicha contratación, de la cláusula social que pretenda incluirse. Así, la utilización de criterios sociales como criterios de adjudicación puede tener grandes ventajas en aquellos contratos en los que no se conoce con exactitud -o el órgano contratante no tiene los medios necesarios para conocerlas características, la disponibilidad y el precio de los productos o servicios más sostenibles, ya que, frente a otras alternativas, el establecimiento de un determinado nivel de rendimiento social como criterio de adjudicación no impide la presentación de ofertas por parte de empresas que no son capaces de alcanzar los requisitos exigidos (Miranzo, 2017) $)^{(37)}$.

Por otro lado, la utilización de criterios de adjudicación de carácter estratégico constituye un mecanismo preciso para valorar los costes de los beneficios que son objeto del criterio de adjudicación, ya que estos costes se reflejarán en el precio u en otros elementos de las ofertas (Arrowsmith, 2018).

Cuando el poder adjudicador esté dotado de un mayor conocimiento del mercado y la consecución del objetivo social adquiera una relevancia mayor en el contexto de la concreta licitación, puede resultar aconsejable configurar esta como condición de ejecución. En todo caso, la introducción la incorporación de cláusulas sociales, cualquiera que sea su naturaleza, debe acompañarse de medidas que permitan comprobar su cumplimiento efectivo en fase de ejecución [STJUE 4/12/2003, Wienstrom, as. C-448/01]. En otro caso, se producirían distorsiones en la competencia sin que pueda garantizarse que dichas distorsiones han sido útiles para la consecución del fin de interés general que justifica su inclusión.

\section{Posteriores desarrollos de la doctrina del tribunal de justicia de la unión europea}

\subsection{Planteamiento}

Tras la entrada en vigor de la Directiva 2014/24/UE, tres sentencias del Tribunal de Justicia han analizado cuestiones relacionadas con la inclusión de cláusulas sociales en la contratación pública. No obstante, dos de estas sentencias siguen aplicando los contenidos de la Directiva 2014/18/CE, dada la fecha en la que surgen los litigios. Aun así, la doctrina elaborada en ambos pronunciamientos es en principio trasladable a la normativa hoy vigente.

4.2. De nuevo sobre la fijación de un salario mínimo como condición de ejecución: ¿Superación de la doctrina Ruffert?

Como ya hemos señalado, la sentencia Ruffert mantuvo una interpretación muy restrictiva de la posibilidad de que las condiciones laborales de los trabajadores adscritos a la ejecución de un contrato público pudieran mejorarse a través de la incorporación de una determinada condición de ejecución.

Posteriormente, la STJUE de 17 de noviembre de 2015, RegioPost, asunto C-115/2014 mantuvo una interpretación más generosa del marco legal. Esta última sentencia consideró admisible una condición de ejecución relativa a salarios mínimos, fijada por una disposición legal para todos los contratos públicos en el ámbito territorial de un determinado Land. Aunque la sentencia encierra ciertas ambigüedades, de la misma puede advertirse también una tendencia a la superación del que se ha llamado "jurisprudencia comunitaria antisocial" del bienio 2007-2008 (Molina, 2016).

De especial importancia es su apartado 65 , según el cual "la limitación del ámbito de aplicación de la norma nacional a los contratos públicos es la mera consecuencia del hecho de que existen normas de Derecho de la Unión que son específicas en este ámbito, en el presente caso las previstas en la Directiva 2004/18" (Molina, 2016) ${ }^{(38)}$. A partir dicha afirmación se puede defender la posibilidad de establecer unas condiciones laborales más generosas para las trabajadores en el ámbito público, siempre eso sí, que se establezcan a través de disposiciones legales ${ }^{(39)}$.

(37) Desde la perspectiva ambiental.

(38) En el mismo sentido, Vázquez (2016, p. 146).

(39) De especial interés son los apartados 74-76 de la sentencia, según los cuales: "Así, en la sentencia Rüffert (C-346/06, EU:C:2008:189), el Tribunal de Justicia se basó en la constatación de que el asunto que dio origen a esa sentencia versaba sobre un convenio colectivo que sólo se aplicaba al sector de la construcción, no cubría los contratos privados y no había sido declarado de aplicación general. Por otro lado, el Tribunal de Justicia señaló que la cuantía de salario mínimo fijado en ese convenio colectivo excedía de la cuantía de salario mínimo aplicable en ese sector en virtud de la AEntG. (...). Pues bien, la cuantía de salario mínimo impuesta por la norma controvertida en el asunto principal está fijada por una disposición legal que, como norma imperativa de protección mínima, se aplica, en principio, de modo general a la adjudicación de todo contrato público en el Land de Renania-Palatinado, con independencia del sector de que se trate. (....). Además, esta disposición legal confiere una protección social mínima dado que, en 
4.3. Protección de salarios en la ejecución del contrato: exigencias del principio de proporcionalidad

La sentencia STJUE de 27 de noviembre de 2019, C 402/18, Tedeschi, analiza la compatibilidad de determinada previsión establecida en el Derecho italiano cuya finalidad es proteger los salarios de los subcontratistas. Esta cuestión se resuelve a la luz de la Directiva 2004/18/CE, aplicable ratione temporis.

Concretamente, la cuestión prejudicial cuestiona la adecuación al Derecho de la Unión europea de la norma italiana que establece que los adjudicatarios deberán aplicar a las prestaciones subcontratadas los mismos precios unitarios que resulten de la adjudicación, con una reducción no superior al $20 \%$.

Pues bien, el Tribunal Europeo considera que tal disposición es contraria al Derecho de la Unión. Para llegar a tal conclusión, el Tribunal parte de que la norma hace menos atractivo el recurso a la subcontratación, cuando, precisamente, la subcontratación permite el acceso de las PYMES a la contratación pública, objetivo perseguido por la Directiva. En este sentido, el Tribunal resalta que ninguno de los objetivos invocados permite justificar el establecimiento de este requisito sobre el precio a abonar a los subcontratistas.

En primer lugar, no puede justificarse la medida en la protección de los trabajadores subcontratados, ya que, según el Tribunal, la medida iría más allá de lo necesario. La normativa sería desproporcionada en este aspecto ya que no deja lugar a una apreciación casuística por parte del poder adjudicador, pues se aplica independientemente de cualquier toma en consideración de la protección social garantizada por las leyes, los reglamentos y los convenios colectivos aplicables a los trabajadores de que se trate. $Y$ en este punto se destaca que:

66 El Derecho italiano dispone que el subcontratista está obligado, al igual que el adjudicatario, a respetar plenamente en relación con sus trabajadores, para las prestaciones realizadas en subcontrata, el tratamiento económico y reglamentario establecido por los convenios colectivos nacionales y territoriales vigentes en el sector y en la zona en la que se realicen las prestaciones. Conforme a estos mismos datos, el adjudicatario es, además, responsable solidario de la observancia de la referida reglamentación por parte del subcontratista.

67 Se desprende igualmente de los datos comunicados al Tribunal de Justicia que, en el caso de autos, la subcontratación de que se trata implica el recurso a cooperativas sociales que disfrutan, con arreglo a la normativa italiana aplicable a tales cooperativas, de un régimen preferencial en materia de fiscalidad, de contribuciones, de remuneración y de seguridad social, y que esta normativa pretende precisamente facilitar la integración en el mercado de trabajo de determinadas personas desfavorecidas permitiendo que se les abone una remuneración inferior a la que se exige en el caso de otras personas que realizan prestaciones análogas. No obstante, incumbe al órgano jurisdiccional remitente efectuar las comprobaciones necesarias a este respecto.

En segundo lugar, la invocación del principio de igualdad no es suficiente para defender la validez del requisito, ya que el mero hecho de que un licitador pueda limitar sus costes gracias a los precios que negocie con los subcontratistas no viola en sí el principio de igualdad de trato, sino que más bien contribuye a una competencia reforzada.

Por último, añade el Tribunal, el límite no puede motivarse invocando el objetivo de asegurar la viabilidad de la oferta y de la correcta ejecución del contrato, ya que existen en el Derecho de la contratación pública otras medidas menos restrictivas que facilitan este objetivo (comprobación de las capacidades de la subcontratista, ofertas anormalmente bajas, etc.).

En definitiva, la sentencia reviste relevancia por varios aspectos. En primer lugar, es patente la inseguridad jurídica que rodea la posibilidad de incorporar consideraciones sociales a la contratación pública. En este aspecto baste señalar que la Comisión europea, que todavía no ha conseguido publicar la actualización de la guía sobre consideraciones sociales a las Directivas de 2014 -como ya hemos destacado-, había defendido en sus observaciones escritas ante el TJUE que la medida era compatible con el Derecho de la Unión. En segundo lugar, es destacable la relevancia que el principio de proporcionalidad adquiere en el ámbito de la contratación estratégica. Este principio exige plantear con exquisita prudencia la adopción de medidas abstractas de aplicación general, al menos en el ámbito de lo social.

\subsection{El cumplimiento de la normativa sociolaboral en fase de ejecución como principio cardinal del Derecho europeo}

La primera sentencia que ha abordado una cuestión relativa a cláusulas sociales a la que es aplicable la Directiva 2014/24/UE es la STJUE de 30 de enero de 2020, C- 395/18, Tim SpA. Relacionada con la necesidad

el momento de los hechos del asunto principal, ni la AEntG ni ninguna otra normativa nacional imponían un salario mínimo de nivel inferior en el sector de los servicios postales. 
de que en la ejecución del contrato se respete la normativa sociolaboral, aborda las consecuencias que respecto a la oferta tiene que el licitador pretenda subcontratar parte de la prestación con una empresa que no respeta las normas relativas al derecho al trabajo de las personas discapacitadas. La sentencia reviste gran interés, pues de las distintas opciones interpretativas acoge aquella que permite reforzar en mayor medida la obligación de que en la ejecución de los contratos se respeten las obligaciones medioambientales, sociales y laborales.

Así, el artículo 71, apartado 6, letra b) de la Directiva 2014/24/UE dispone los Estados miembros podrán tomar las medidas oportunas para evitar el incumplimiento de las obligaciones aplicables en materia medioambiental, social o laboral. En particular:

Los poderes adjudicadores, (...) podrán comprobar (...) si concurren motivos para excluir a algún subcontratista con arreglo al artículo 57. En tales casos, el poder adjudicador exigirá que el operador económico sustituya al subcontratista que haya incurrido (...).

De esta forma, la consecuencia que prevé el Derecho europeo en los supuestos en los que el subcontratista esté incurso en causa de exclusión por incumplimiento de obligaciones sociolaborales es la sustitución del subcontratista, sin que se prevea expresamente la exclusión del licitador. Sin embargo, el Derecho italiano -aplicable a la cuestión prejudicial que es origen de la sentencia- va más allá al imponer la exclusión del licitador ${ }^{(40)}$. Pues bien, el Tribunal Europeo confirma que esta consecuencia más severa no vulnera la Directiva 2014/24/UE. Para fundamentar esta interpretación, el TJUE hace exclusiva referencia a los artículos 18.2 y artículo 57.4 a) de la Directiva 2014/24/UE.

Así, por un lado, se destaca que:

al establecer en el apartado 2 de dicho artículo que los operadores económicos deben cumplir, en la ejecución del contrato, las obligaciones en materia medioambiental, social y laboral, el legislador de la Unión quiso erigir este requisito en principio, al igual que los demás principios contemplados en el apartado 1 del citado artículo, a saber, los principios de igualdad de trato, de no discriminación, de transparencia y de proporcionalidad, así como de prohibición de excluir la contratación del ámbito de aplicación de la Directiva 2014/24 o de restringir artificialmente la competencia. De ello se deduce que un requisito de este tipo constituye, en la configuración general de la citada Directiva, un valor cardinal por cuyo respeto deben velar los Estados miembros". [énfasis agregado].
Por otro lado, se subraya que:

cuando la normativa nacional establece que tiene la facultad -o incluso la obligación- de excluir al operador económico (...) la entidad adjudicadora está obligada, en aras de la observancia del principio de igualdad de trato, a comprobar la existencia de cualquier incumplimiento de tales obligaciones [en materia ambiental, social y laboral] no solo en relación con todos los operadores económicos que han presentado ofertas, sino también con respecto a todos los subcontratistas que los operadores económicos hayan mencionado en sus respectivas ofertas.

Ahora bien, para que la exclusión del operador económico sea conforme al Derecho europeo ha de respetar el principio de proporcionalidad. Lo que implica que: en primer lugar, el operador económico debe tener la posibilidad de demostrar su fiabilidad a través de la presentación de medidas correctoras, al amparo del artículo 57.6 de la Directiva; en segundo lugar, el poder adjudicador debe tener la facultad de valorar de forma individualizada las circunstancias particulares del caso.

En este sentido, debe destacarse que la legislación nacional aplicable exigía la presentación de una terna de subcontratistas en la oferta, sin que ello supusiese la obligación por parte del operador económico de subcontratar la prestación durante la ejecución del contrato. En estas circunstancias, la exclusión es fácilmente calificable como desproporcionada. Otro de los aspectos que deben ser valorados por el poder adjudicador son los medios de que disponía el operador económico que ha presentado la oferta para comprobar la existencia de un incumplimiento por parte de los subcontratistas.

En definitiva, la sentencia tiene el gran valor de colocar en pie de igualdad el cumplimiento de la normativa sociolaboral con principios de la contratación más clásicos

(40) El artículo 80, apartado 5, letra i) del "Código de Contratos Públicos" italiano establece: "Las entidades adjudicadoras excluirán de la participación en un procedimiento de licitación al operador económico que se encuentre en alguna de las situaciones que se exponen a continuación, lo que se aplicará asimismo a un subcontratista en los casos previstos en el artículo 105, apartado 6, cuando:...] i) el operador económico no presente la certificación a que se refiere el artículo 17 de la Ley 68 (...) o no autocertifique la existencia de dicho requisito (...)". Este último precepto establece que las empresas que participen en licitaciones públicas estarán obligadas a presentar, con carácter previo y bajo pena de exclusión, un certificado expedido por el representante legal respectivo que acredite que la empresa cumple las normas relativas al derecho al trabajo de las personas discapacitadas. 
como el de libre competencia. No obstante, una vez más, la inclusión de una cláusula social debe respetar el test de proporcionalidad, que se convierte nuevamente en un elemento de trascendental importancia.

\section{Recapitulación}

Durante los más de veinte años que han transcurrido desde la sentencia Beentjes se ha esbozado una evolución, no sin ciertas contradicciones, tendentes primero a admitir, y luego a consagrar, la utilización estratégica de la contratación pública en el ámbito del Derecho europeo. No obstante, introducir los principios de promoción social junto a los principios clásicos de igualdad y concurrencia no ha resultado en absoluto sencillo. Aunque desde la aprobación de la Directiva 2014/24/ UE el impulso de la contratación estratégica es un elemento caracterizador del Derecho europeo de los contratos públicos, la plasmación de cláusulas sociales en la contratación pública sigue marcada por un importante halo de inseguridad jurídica. Y la ausencia de certeza en el Derecho dificulta de hecho que los órganos de contratación puedan hacer un uso más extensivo de la contratación social.

Esta limitación se nos antoja de difícil solución a falta del documento orientativo de la Comisión que siente las bases de la utilización de cláusulas sociales en la contratación pública, porque aunque en algunos ordenamientos nacionales o en las guías aprobadas por distintas administraciones nacionales se proponen soluciones con cierto grado de abstracción -que garantizan la seguridad jurídica-, en la práctica estas soluciones desconocen que el Derecho europeo exige que caso a caso se realice una ponderación de los distintos principios en juego. La articulación de todos ellos depende de la aplicación del principio de proporcionalidad. De esta forma, para alcanzar un grado deseable de seguridad jurídica respecto a la utilización de cláusulas sociales en la contratación pública -a falta de un documento orientativo suficientemente sólido-, será preciso una mayor experiencia aplicativa que permita adquirir suficiente pericia en la aplicación del triple test de proporcionalidad. En este sentido, un elemento fundamental en la introducción de cada cláusula será su motivación.

En todo caso, la utilización de la contratación pública como elemento de política social de forma exitosa no dependerá exclusivamente de la calidad de la norma ni de la destreza en su interpretación, sino fundamentalmente del acierto en su ejecución. Y ello plantea desafíos que van más allá de lo estrictamente jurídico. Será preciso así que exista un alto grado de compromiso político, que se favorezca una contratación menos burocratizada y más profesional (Gimeno, 2014) $)^{(41)}$, y que se formulen estrategias de contratación claras $^{(42)}$. No debe desdeñarse la posibilidad de plantear reformas organizativas, dentro de un planteamiento holístico en el seno de cada organización ${ }^{(43)}$. Y finalmente, la posibilidad de aprender de experiencias previas y de conseguir impactos significativos dependerá de la capacidad de evaluación de las iniciativas desplegadas ${ }^{(44)}$.

La práctica demuestra así que una utilización inadecuada de las cláusulas estratégicas no sólo compromete la realización del objetivo político perseguido -en aquel caso, la creación de empleo-, sino también la realización de los principios de igualdad, transparencia y eficiencia. La contratación estratégica es transversal. Pero será preciso valorar cuidadosamente el objetivo a perseguir y elegir el medio idóneo, de forma que se tienda a lograr el deseable equilibrio entre los distintos fines y principios que el procedimiento de licitación ha de armonizar.

(41) Sobre ello véase Recomendación de la Comisión de 3.10.2017 "Construir una arquitectura para la profesionalización de la contratación pública", C (2017) 6654 final. Entre las recomendaciones se encuentra facilitar y fomentar el pensamiento estratégico.

(42) Sobre este aspecto insiste la citada Comunicación "Conseguir que la contratación pública funcione en Europa y para Europa", p. 7. En relación con el ello, el artículo 334.2 LCSP establece como uno de los objetivos de la Estrategia Nacional de Contratación Pública "utilizar las posibilidades de la contratación pública para apoyar políticas ambientales, sociales y de innovación".

(43) Véase el Estudio "Strategic use of public procurement in promoting green, social and innovation policies" realizado a instancias de la Comisión Europea, diciembre 2015. Como se afirma en la p. 98, la contratación pública estratégica comprende tres áreas de políticas públicas diferentes -compra ecológica, compra socialmente responsable y compra innovadora- que están vinculadas de múltiples formas. Sin embargo, muy a menudo dichas políticas se tratan como ámbitos diferenciados y en ello no se implica directamente a los órganos responsables de la contratación pública, que se sienten ajenos a estas políticas públicas.

(44) Así, el estudio Estudio "Strategic use of public procurement in promoting green, social and innovation policies" pone de manifiesto que la monitorización representa el área de mayor debilidad de la compra pública estratégica. Y aunque se llevan a cabo iniciativas en los distintos Estados Miembros, a menudo se realiza de forma irregular. De esta forma, es difícil obtener un marco preciso de los resultados de la contratación pública estratégica y aprender lecciones para el diseño de públicas. 
Por otro lado, la incorporación de cláusulas estratégicas exige que se realice el consecuente control del cumplimiento efectivo de la cláusula en cuestión durante la fase de ejecución. Y ello, independientemente de la fase en la que esta cláusula entre a formar parte del contenido obligacional pactado. Porque de otro modo, durante la fase de licitación no se llevará a cabo una competencia real, sino meros juegos de ilusión y artificio. De nada sirve el respeto escrupuloso en la fase de adjudicación de los principios de igualdad y transparencia si, tras la conclusión del procedimiento, el cumplimiento de lo ofertado por el licitador (o de lo exigido por el poder público) queda al albur del adjudicatario.

\section{Referencias bibliográficas}

Arrowsmith, S. (2014). The Law of Public and Utilities Procurement. Sweet and Maxwell, 3.

Bordalo, F. (2014). Award Criteria in the New EU Directive on Public Procurement. Public Procurement Law Review, 23.

Díez, S. (2017). Las cláusulas sociales en la contratación pública. Anuario de la Facultad de Derecho de la Universidad Autónoma de Madrid, 21, 195-219. http://hdl.handle.net/10486/686468

Edler, J. \& Georghiou, L. (2007). Public procurement and innovation-Resurrecting the demand side. Research Policy, 36, 949-963. https://doi. org/10.1016/j.respol.2007.03.003

Gallego, C. (2019). Posibilidades y límites generales de las cláusulas sociales y medioambientales como criterios de adjudicación y de desempate. En Pardo, M. \& Sánchez, A. (dirs.), Inclusión de cláusulas sociales y medioambientales en los pliegos de contratos públicos: guía práctica profesional (pp. 107-125). Aranzadi.
Gimeno, J. M. (2006). La nueva contratación pública europea y su incidencia en la legislación española. La necesaria adopción de una nueva Ley de contratos públicos y propuestas de reforma. Civitas.

Gimeno, J. M. (2014). El nuevo paquete legislativo comunitario sobre contratación pública. De la burocracia a la estrategia: (el contrato público como herramienta del liderazgo institucional de los poderes públicos). Aranzadi.

González, V. (2015). Sostenibilidad social y ambiental en la Directiva 2014/24/UE de contratación pública. Revista Española de Derecho Europeo, 56, 13-42.

Medina, T. (2011). Comprando para asegurar nuestro futuro: la utilización de la contratación pública para la consecución de los objetivos políticos de la Unión Europea. En Gimeno, J. M. (dir.), Observatorio de Contratos Públicos. Aranzadi.

Medina, T. (2012). La contratación pública socialmente responsable a través de la jurisprudencia del Tribunal de Justicia de la Unión Europea. REDA, 153, 213-240.

Meilan, J. L. (2013). Las prerrogativas de la Administración en los contratos administrativos: propuesta de revisión. Revista de Administración Pública, 191, 11-41.

Miranzo, J. (2017). Los criterios de adjudicación ambientales en las Directivas de 2014. En Razquin, M. \& Alenza, J. (coord.). Nueva contratación pública: mercado y medio ambiente (pp. 383-404), Aranzadi.

Molina, C. (2016). Cláusulas sociales, contratación pública: del problema de su "legitimidad" al de sus "limites. Temas Laborales: Revista andaluza de trabajo y bienestar social, 135, 79-110.

Moreno, J. \& Pleite, F. (2009). La nueva Ley de Contratos del Sector Público. Estudio sistemático, 2.

Pernas, J. (2011). Contratación Pública Verde. La Ley.

Pernas, J. (2013). Contratación Pública Estratégica. Aranzadi.

Razquin, M. (2017). Nueva contratación pública: mercado y medio ambiente. Aranzadi.

Rodriguez, J. (2013). La contratación del sector público como política pública. En Contratación Pública Estratégica. Aranzadi.

Vázquez, E. (2016). El pago de un salario mínimo como condición especial de ejecución en los contratos públicos. Comentario a la STJUE en el caso Regio Post. Contratación Administrativa Práctica, 146, 28-41. 